\title{
Efluente de Tambacus (Piaractus mesopotamicus Holmberg, 1887 X Colossoma macropomum Cuvier, 1818) para produção de alfaces (Lactuca sativa L.) em sistema aquapônico
}

\author{
Otávio Miranda Verly \\ Instituto Federal de Educação, Ciência e Tecnologia de Mato Grosso, Campus Cáceres \\ (verly.miranda@gmail.com) \\ Monique Virães Barbosa dos Santos \\ Instituto Federal de Educação, Ciência e Tecnologia de Mato Grosso, Campus Cáceres \\ (monique.santos@cas.ifmt.edu.br)
}

Cristian Jacques Bolner de Lima

Instituto Federal de Educação, Ciência e Tecnologia de Mato Grosso, Campus Cáceres

(cristian.lima@cas.ifmt.edu.br)

Natália Cardoso Procópio

Instituto Federal de Educação, Ciência e Tecnologia de Mato Grosso, Campus Cáceres

(nataliac.ardosoproc.opio@gmail.com)

Júlio Cézar Passos

Instituto Federal de Educação, Ciência e Tecnologia de Mato Grosso, Campus Cáceres

(passos.julio.jcp@gmail.com)

\begin{abstract}
Resumo: A aquaponia alia a produção de vegetais e peixes, garantindo produção com menor impacto ao meio ambiente. Neste sistema, a água de drenagem do cultivo dos peixes, rica em matéria orgânica, é reaproveitada como fonte de nutrientes para os vegetais. O objetivo deste trabalho foi projetar um sistema de aquaponia de baixo custo e investigar seu funcionamento considerando a qualidade de água e o crescimento de tambacus e alfaces. $O$ trabalho foi realizado no Laboratório de Piscicultura do IFMT Campus Cáceres, por 67 dias. O sistema foi composto por duas caixas, sendo uma de 72L, onde foram colocados seis juvenis de tambacus e uma bomba para recirculação; e outra de 50L, onde foram plantadas 12 mudas de alface em argila expandida. Os peixes foram alimentados duas vezes ao dia com ração extrusada. Foram feitas análises da temperatura, $\mathrm{pH}$, nitrito e amônia da água duas vezes por semana; enquanto a aferição do comprimento e peso dos peixes e das alfaces ocorreu no início e no fim. Foi observado que os tambacus e as alfaces obtiveram um baixo desempenho, e ainda que os valores de amônia e nitrito, que estavam tóxicos no início, reduziram-se a zero ao longo do experimento. A proporção peixevegetal utilizada foi insuficiente para atender a demanda nutricional das alfaces.
\end{abstract}

Palavras-chave: Cultivo integrado; Aquaponia; Piscicultura; Reuso de água.

\section{Tambacus effluent (Piaractus mesopotamicus Holmberg, 1887 X Colossoma macropomum Cuvier, 1818) for lettuce producing (Lactuca sativa $L$.) in aquaponic system}

Abstract: Aquaponia combines the production of vegetables and fish, ensuring production with less impact to environment. In this system, water from drainage of the cultivation of fish rich in organic material are reused as a source of nutrients for the plants. The objective of this work was to design an aquaponics system of low-cost and investigate their operation considering water quality and the growth of tambacus and lettuces. The work went conducted in the pisciculture laboratory of the IFMT Campus Cáceres, for 67 days. The system was composed of two boxes, one of $72 \mathrm{~L}$, where were placed six juvenile tambacus and a Recirculation pump; and another of $50 \mathrm{~L}$, where were planted 12 seedlings of lettuce in expanded clay. The fishes were feed twice a day with extruded food. There 
were make out analysis of temperature, $\mathrm{pH}$, nitrite and ammonia from the water 2 times a week; while the measurement of the length and weight of the fishes and vegetables occurred at the beginning and end. It was observed that the tambacus and the lettuces had a low performance, and that the values of ammonia and nitrite, which were toxic at the beginning, went been reduced to zero over the experiment. The proportion animal-vegetable used was insufficient to meet the nutritional requirement of lettuces.

Keywords: Integrated cultivation; Aquaponics; Pisciculture; Reuse of water.

\section{INTRODUÇÃO}

Com o aumento rápido e incessante da população mundial, que já ultrapassa os sete bilhões de pessoas, os recursos hídricos estão se tornando cada vez mais limitados. A produção agrícola é a principal forma de consumo da água doce no mundo, de modo que sua escassez está diretamente ligada à segurança alimentar humana. Assim, técnicas de cultivo alternativas, que proporcionem a melhor utilização da água, podem assegurar a produção alimentícia para o futuro (ARAÚJO, 2015).

Neste cenário, sistemas de produção que possibilitam a reutilização ou redução no uso de insumos são fundamentais para garantir a disponibilização de alimentos ecologicamente corretos. Assim, o método de produção em aquaponia é considerado um importante processo de produção de baixo impacto (HUNDLEY, 2013), tendo em vista que a aquicultura convencional pode contribuir para a degradação da qualidade da água dos corpos receptores dos efluentes, atuando como uma atividade poluidora do meio ambiente (MACINTOSH e PHILLIPS, 1992; CHOPIN e SAWHNEY, 2009; PHILLIPS, 2009), pois a principal causa do enriquecimento da água oriunda de viveiros de aquicultura são as substâncias dissolvidas, ou em suspensão, contidas nos efluentes. Estas substâncias são provenientes das excretas e sobras de rações, que são convertidas em materiais orgânicos suspensos, dióxido de carbono, nitrogênio $(\mathrm{N})$ amoniacal, fosfatos e outros compostos (MONTOYA et al., 2000).

O sistema aquapônico é o resultado da combinação entre aquicultura, produção de organismos aquáticos, e hidroponia, produção de plantas sem solo. Refere-se à produção integrada de organismos aquáticos, sobretudo peixes, e o cultivo de vegetais hidropônicos (CARNEIRO et al., 2015; BIALLI e CRUZ, 2016) em 
sistema de cativeiro de forma que haja benefícios para ambos (RAKOCY et al., 2004).

A integração entre o componente vegetal e animal pode permitir que as plantas utilizem os nutrientes provenientes da água do cultivo dos peixes, melhorando a qualidade da água (QUILLÉRÉ et al.,1995). Neste sistema, além dos peixes e plantas, existem ainda bactérias que promovem a transformação dos nutrientes necessários ao crescimento dos vegetais, os quais são fornecidos nas excretas e outros resíduos metabólicos dos peixes. Desta forma, a recirculação só é possibilitada pela absorção da matéria orgânica e dos resíduos inorgânicos gerados no sistema (TROELL, 2008).

De acordo com Diver (2006), esta atividade está ganhando atenção como um sistema biointegrado de produção de alimentos que pode ser realizado em sistemas fechados de circulação. Entre as vantagens da aquaponia, incluem-se o prolongado reuso da água e a integração dos sistemas de produção de organismos aquáticos e plantas, que permitem uma diminuição dos custos (ADLER et al., 2000) e melhoram a rentabilidade dos sistemas de aquicultura. Buss et al. (2015) consideram o fato de que a aquaponia pode ser implantada em pequenos espaços, como fator estimulante à agricultura familiar em ambiente urbano. Por outro lado, acredita-se que a água derivada da aquicultura, na maioria das vezes, seja deficiente em alguns nutrientes requeridos pelas plantas cultivadas em sistema hidropônico, sendo necessária a suplementação destes (RAKOCY; HARGREAVES e BAILEY, 1989).

Apesar da aquicultura e da hidroponia serem práticas de produção de alimentos estudadas há mais de cinquenta anos, as pesquisas em aquaponia somente começaram a apresentar seus resultados mais expressivos na última década. Assim, a literatura acadêmica brasileira ainda é pobre e incipiente sobre o tema, sendo que apenas nos últimos anos pesquisadores de algumas universidades brasileiras e da Empresa Brasileira de Pesquisa Agropecuária (EMBRAPA) iniciaram suas pesquisas nesta área (CARNEIRO et al., 2015; BIALLI e CRUZ, 2016).

Desta forma, objetivou-se com este trabalho testar um sistema de aquaponia de baixo custo e investigar seu funcionamento considerando a qualidade de água e o crescimento de tambacus (Piaractus mesopotamicus Holmberg, $1887 \mathrm{X}$ Colossoma macropomum Cuvier, 1818) e alfaces (Lactuca sativa L.). 


\section{METODOLOGIA}

O experimento foi realizado no período de julho a setembro de 2016, no Laboratório de Piscicultura do Instituto Federal de Educação, Ciência e Tecnologia do Mato Grosso (IFMT) Campus Cáceres, Prof. Olegário Baldo, cujas coordenadas geográficas são $16^{\circ} 13^{\prime} 55,1^{\prime \prime}$ de latitude sul e 5751'46,2” de longitude oeste, com altitude de $117 \mathrm{~m}$.

O sistema de aquaponia montado foi composto por duas caixas plásticas. A primeira, com capacidade de 72 litros, para a criação dos peixes, e outra, de 50 litros, preenchida com argila expandida para fixação e cultivo dos vegetais. $O$ sistema de recirculação de água funcionou da seguinte forma, uma bomba de 150 litros/hora bombeava a água da caixa de criação dos peixes para a caixa de cultivo dos vegetais através de uma mangueira, e o retorno da água acontecia por gravidade, uma vez que as caixas foram sobrepostas. O nível de água na caixa de cultivo vegetal era regulado por um sifão confeccionado com tubos e conexões de PVC. A água da caixa de criação dos peixes foi constantemente oxigenada por um compressor de ar, e seu nível foi mantido pela reposição periódica da água perdida por evaporação superficial e evapotranspiração dos vegetais.

Os peixes foram adquiridos de um piscicultor do município de Glória D’Oeste, Mato Grosso. Foram utilizados juvenis de tambacus, peixe híbrido obtido através do cruzamento entre a fêmea de tambaqui (Colossoma macropomum Cuvier, 1818) e o macho de pacu (Piaractus mesopotamicus Holmberg, 1887). Na caixa de cultivo de peixes, foram alojados 6 juvenis com peso médio inicial de 35,0 g $( \pm 3,33)$ e comprimento total médio inicial de $11,8 \mathrm{~cm}( \pm 0,60)$. Os peixes foram alojados três semanas antes da introdução das alfaces no sistema de aquaponia, a fim de aclimatá-los à estrutura e, principalmente, colonizar o filtro biológico com bactérias nitrificantes.

Após este período, foram acomodadas, na caixa de cultivo vegetal 12 mudas de alface, sendo seis da variedade americana e seis da variedade lisa. As mudas foram distribuídas aleatoriamente, sendo que cada uma possuía uma área média de $205 \mathrm{~cm}^{2}$ para se desenvolver. Os parâmetros biométricos iniciais dos vegetais encontram-se na Tabela 3.

Os peixes foram alimentados duas vezes ao dia com ração do tipo extrusada, $36 \%$ de proteína bruta e tamanho de 3 a $4 \mathrm{~mm}$. A nutrição da parte vegetal do 
sistema se deu, exclusivamente, pela absorção de nutrientes derivados dos dejetos liberados pelos peixes, sendo que não houve acréscimo de fertilizantes. Estes resíduos são ricos em $\mathrm{N}$ na forma de amônia $\left(\mathrm{NH}_{3}\right)$, porém as plantas o utilizam na forma de nitrato $\left(\mathrm{NO}_{3}{ }^{-}\right)$. Assim, a argila expandida, além de sustentar as mudas de alface, serviu como substrato para colonização das bactérias que transformam a amônia em nitrito, e este em nitrato.

Duas vezes por semana, durante os 67 dias de desenvolvimento do experimento, foram avaliadas algumas variáveis da água como: temperatura, com auxílio de termômetro de mercúrio; níveis de $\mathrm{pH}$, amônia e nitrito, por meio de reagentes específicos para teste rápido; e a condutividade elétrica, utilizando-se um condutivimetro.

A pesagem dos peixes foi feita semanalmente, e a aferição do comprimento total foi realizada no início, no meio e no final do período de avaliação. Em relação às alfaces, as variáveis biométricas avaliadas foram: número de folhas e altura da parte aérea, as quais foram mensuradas no início, metade e final do experimento; enquanto altura radicular, diâmetro do coleto, e peso foram aferidos no início e no fim do estudo. As avaliações de comprimento e altura foram realizas com paquímetro digital Western ${ }^{\circledR}$ PRO DC-6 e as de peso com balança Balmak ${ }^{\circledR}$ SUPERINOX-5. Para obtenção de biomassa animal, foram somados os pesos de todos os peixes, no início, assim como no fim do experimento; já a fitomassa fresca, foi obtida através da soma dos exemplares de alface.

Os dados coletados foram tabulados e processados no Software Microsoft Office Excel 2013, no qual foram calculadas as médias e desvios das variáveis.

\section{RESULTADOS E DISCUSSÃO}

Os parâmetros de temperatura, $\mathrm{pH}$ e amônia encontravam-se dentro da faixa recomendada para o cultivo de peixes e vegetais, exceto o nitrito (Tabela 1). 
Tabela 1. Médias dos parâmetros de qualidade da água no sistema de aquaponia.

\begin{tabular}{ll}
\hline Parâmetros & Valores médios \\
\hline Temperatura $\left({ }^{\circ} \mathrm{C}\right)$ & $22,3 \pm 2,82$ \\
$\mathrm{pH}$ & $7,5 \pm 0,41$ \\
Amônia total $(\mathrm{mg} / \mathrm{L})$ & $0,539 \pm 0,62$ \\
Amônia tóxica $(\mathrm{mg} / \mathrm{L})$ & $0,089 \pm 0,15$ \\
Nitrito $(\mathrm{mg} / \mathrm{L})$ & $0,882 \pm 1,03$ \\
Condutividade elétrica $\left(\mathrm{dS} \mathrm{m}^{-1}\right)$ & $0,483 \pm 0,04$ \\
\hline
\end{tabular}

Ainda sobre as análises de água, foi observado que o teor de amônia foi reduzido de 0,780 mg/L, para 0,002 mg/L, após o 11ํ dia de experimento (Figura 1). O sistema mostrou-se eficaz para o tratamento do efluente proveniente do sistema de aquicultura, de modo que em 79\% das análises o teor de amônia tóxica não representava risco para os animais, o que demonstra eficiência bacteriana na conversão de amônia em nitrito.

O nitrito teve os valores reduzidos de $2,8 \mathrm{mg} / \mathrm{L}$ para $1,0 \mathrm{mg} / \mathrm{L}$ no $4^{\circ} \stackrel{\mathrm{dia}}{ }$, e para zero, no $7^{0}$ dia, após a introdução dos vegetais. Para esta análise o valor médio foi de $0,882 \mathrm{mg} / \mathrm{L}$, sendo que $58 \%$ das análises apresentaram teores ideais ou aceitáveis de nitrito (Gráfico 1), o que demostra menor desempenho do sistema bacteriano responsável pela transformação de nitrito em nitrato.

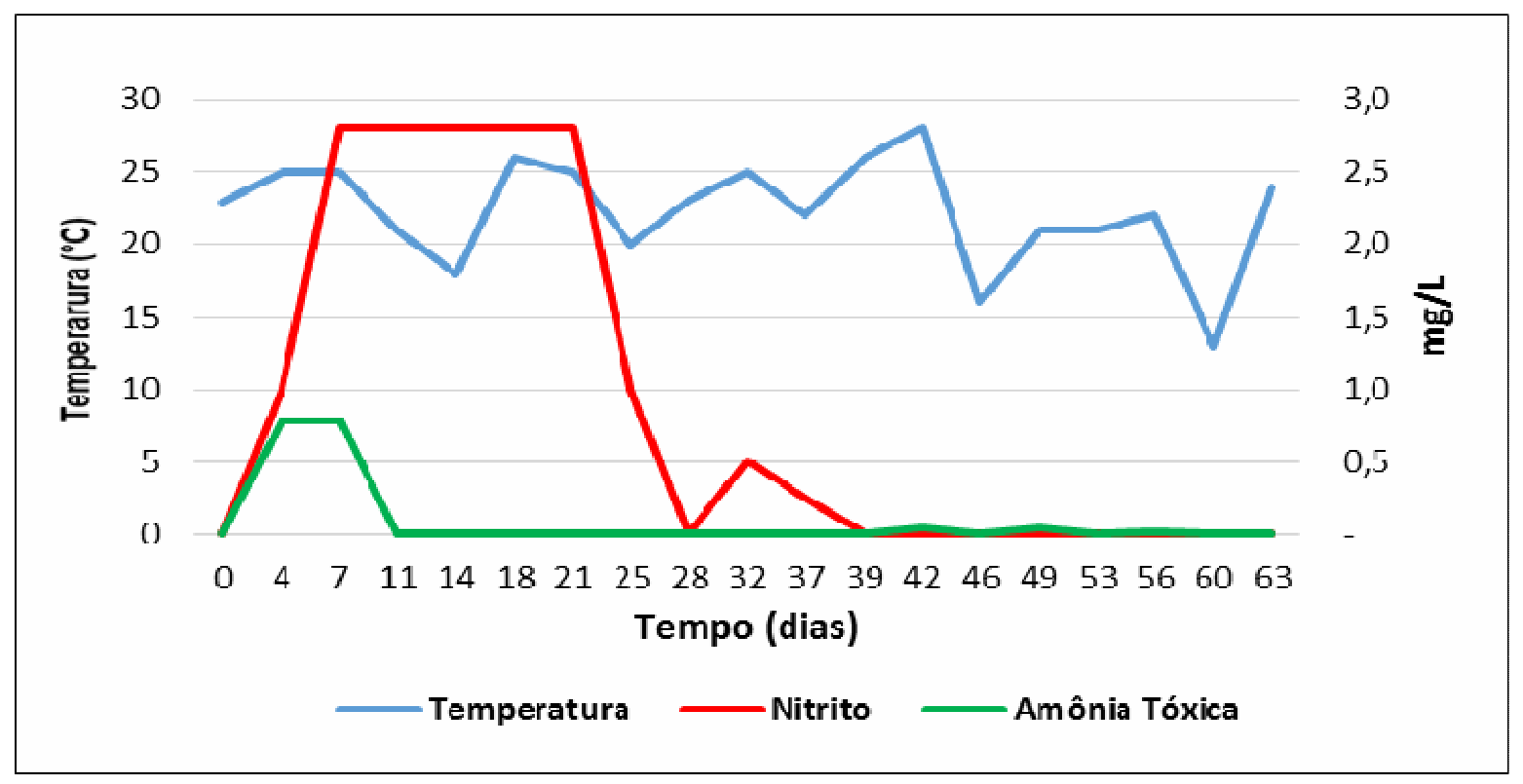

Figura 1. Temperatura da água, concentração de nitrito e amônia tóxica em função do tempo no sistema aquapônico testado. 
Segundo Moro et al. (2013), o valor letal de amônia tóxica para os peixes é de $0,20 \mathrm{mg} / \mathrm{L}$, enquanto o valor máximo de nitrito tolerado pela maioria das espécies de peixes é de $0,50 \mathrm{mg} / \mathrm{L}$. Assim, os peixes ficaram expostos a níveis letais de amônia tóxica até $07^{0}$ dia do experimento, sendo que, depois disso, os níveis caíram para leituras inferiores a $0,047 \mathrm{mg} / \mathrm{L}$. Já os valores de nitrito só decresceram à níveis não letais a partir do $28^{\circ}$ dia, coincidindo com a introdução das alfaces.

A taxa de sobrevivência foi de $100 \%$, sendo que os peixes obtiveram pequeno ganho de peso $(2,67 \mathrm{~g})$, encerrando o período de análise com peso médio de 37,67 g. O comprimento médio final dos peixes foi de $12,95 \mathrm{~cm}$, ou seja, um crescimento médio de 1,12 cm (Tabela 2).

Tabela 2. Parâmetros zootécnicos dos juvenis de tambacus no início e no fim do período avaliado.

\begin{tabular}{llll}
\hline Parâmetros zootécnicos & Início & Fim & Incremento \\
\hline Peso médio $(\mathrm{g})$ & $35,00 \pm 3,33$ & $37,67 \pm 2,89$ & $+2,67$ \\
Biomassa $(\mathrm{g})$ & 210 & 226 & +16 \\
Comprimento total médio $(\mathrm{cm})$ & $11,83 \pm 0,60$ & $12,95 \pm 0,47$ & $+1,12$ \\
\hline
\end{tabular}

Infere-se que estes resultados de baixo rendimento dos tambacus ocorreram devido ao alto teor de amônia e nitrito encontrado nos primeiros dias de investigação. Estes teores estavam tóxicos no início, desta forma, comprometeram o crescimento dos peixes. Além disso, houve quedas bruscas de temperatura durante o período experimental, o que contribuiu para oscilação de peso dos peixes (Figura 2), por serem animais pecilotérmicos, não consumiram a ração e acabaram não se desenvolvendo.

Em relação às alfaces, o índice de mortalidade para a variedade americana foi de $16,7 \%$ (1 indivíduo), e para a variedade lisa esta percentagem foi de $66,7 \%$ (4 indivíduos). Os dados sobre o desenvolvimento das alfaces estão apresentados na tabela 3. Observou-se que para a variedade americana o comprimento aéreo final médio foi de 173,80 mm, correspondendo a um crescimento de 149,35 mm. Para a alface lisa o comprimento médio final da parte aérea foi $212,50 \mathrm{~mm}$, tendo um incremento médio da parte aérea de 179,7 mm (Tabela 3). Considerando-se esta variável, verificou-se que o crescimento da variedade lisa foi maior que a variedade americana. 


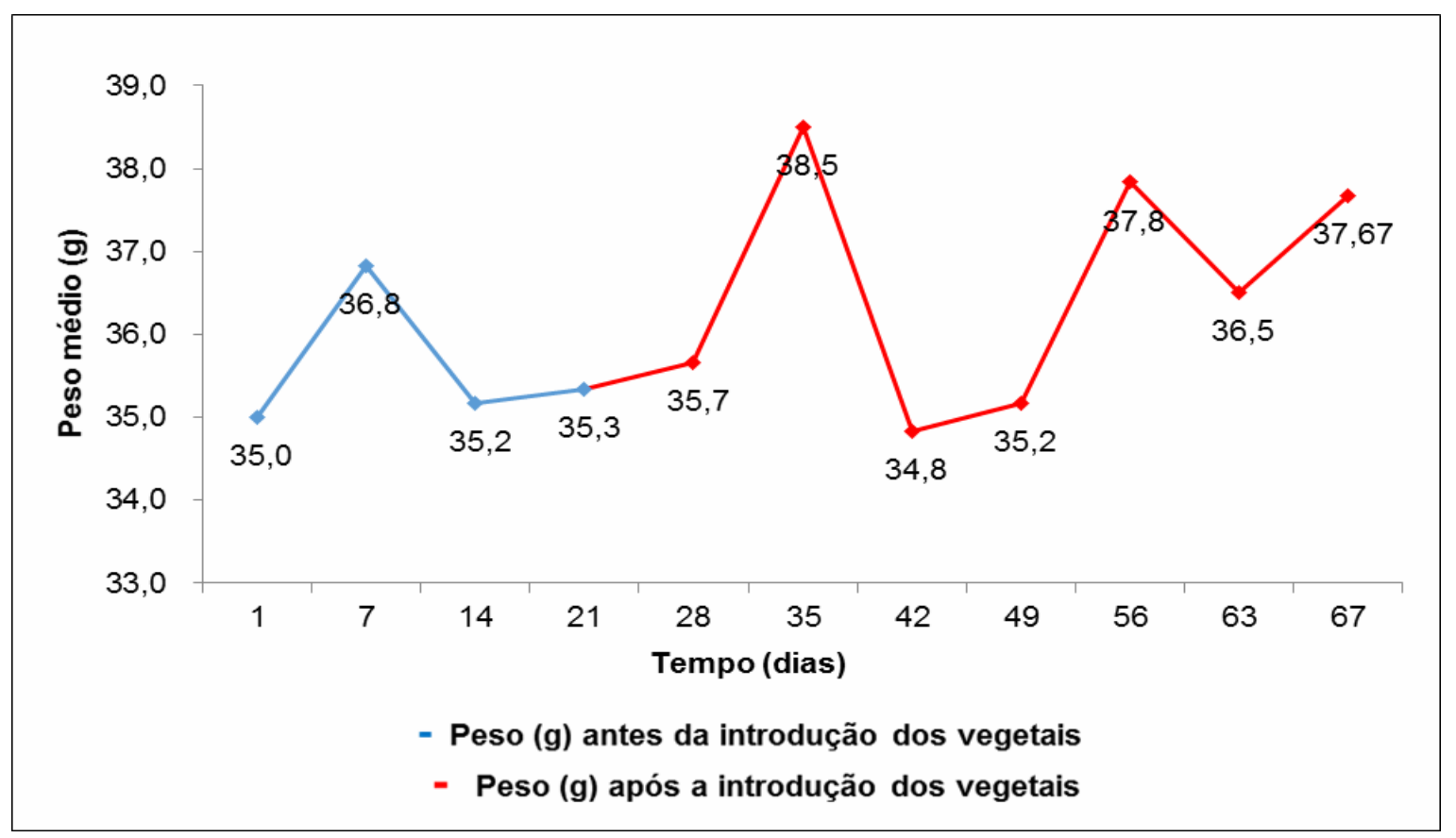

Figura 2. Peso dos tambacus em função do tempo, antes e depois da introdução dos vegetais no sistema aquapônico.

A variedade lisa também apresentou maior desenvolvimento em relação ao número de folhas, de modo que esta obteve um acréscimo médio de 5,7 folhas, assim, o número médio final de folhas foi 9,5, valor maior do que o encontrado na variedade americana, que teve um incremento médio de 1,4 folhas, finalizando o experimento com 6,4 folhas em média.

Tabela 3. Parâmetros de crescimento vegetal observados nos indivíduos de alface no início e ao final do período avaliado.

\begin{tabular}{|c|c|c|c|c|}
\hline & Parâmetros & Início & Fim & Incremento \\
\hline \multirow{6}{*}{$\frac{1}{<}$} & Número de folhas médio & $5,00 \pm 0,00$ & $6,40 \pm 0,48$ & $+1,40$ \\
\hline & Comprimento aéreo médio (mm) & $24,55 \pm 3,98$ & $173,80 \pm 27,76$ & $+149,25$ \\
\hline & Comprimento radicular médio ( $\mathrm{mm})$ & $93,18 \pm 13,82$ & $77,40 \pm 13,68$ & $-15,78$ \\
\hline & Diâmetro do coleto médio (mm) & $2,58 \pm 0,32$ & $2,76 \pm 0,17$ & $+0,18$ \\
\hline & Peso médio $(\mathrm{g})$ & $0,85 \pm 0,27$ & $1,17 \pm 0,74$ & $+0,89$ \\
\hline & Fitomassa fresca $(\mathrm{g})$ & 5,1 & 5,85 & $+0,75$ \\
\hline & Número de folhas médio & $3,83 \pm 0,28$ & $9,50 \pm 4,50$ & $+5,67$ \\
\hline & Comprimento aéreo médio $(\mathrm{mm})$ & $32,77 \pm 4,26$ & $212,50 \pm 117,50$ & $+179,73$ \\
\hline & Comprimento radicular médio $(\mathrm{mm})$ & $50,70 \pm 3,53$ & $65,50 \pm 5,50$ & $+14,80$ \\
\hline & Diâmetro do coleto médio (mm) & $2,63 \pm 0,28$ & $3,40 \pm 0,70$ & $+0,77$ \\
\hline & Peso médio (g) & $1,30 \pm 0,17$ & $3,25 \pm 2,55$ & $+1,95$ \\
\hline & Fitomassa fresca $(\mathrm{g})$ & 7,8 & 6,5 & $-1,3$ \\
\hline
\end{tabular}

Em ambas as variedades de alface foram verificados baixo desempenho de crescimento das partes aérea e radicular, reduzido ganho de peso e queda 
prematura das folhas mais velhas. Estes mesmos sintomas foram constatados por Almeida et al. (2011), quando aplicaram solução nutritiva deficiente em nitrogênio em mudas de alface. Desta forma, pode-se correlacionar o baixo desenvolvimento aéreo dos vegetais à deficiência de nitrogênio. Esta hipótese pode ser embasada, ainda, pelo fato de que a produção de dejetos ricos em $\mathrm{N}$ pelos peixes foi pequena, pois se tratavam de juvenis. Além do que, a proporção de animais para plantas (1:2), pode ter sido pequena, haja vista que Diver (2006) menciona proporções entre 1:1 e 1:4. Ainda, em relação à deficiência de $\mathrm{N}$, sintomas como o amarelecimento acentuado nas folhas, verificado por Almeida et al. (2011) e Tischer e Siqueira Neto (2012), também foram observadas neste estudo.

Assim como nos estudos de Silva et al. (2011), os indivíduos de alface apresentaram severa murcha diurna, sendo que no trabalho destes autores tal sintoma foi decorrente da deficiência de cálcio. As folhas apresentaram-se delgadas e com alto grau de encarquilhamento, sendo possível inferir que estes sintomas são causados também pela deficiência deste nutriente.

O reduzido desenvolvimento dos vegetais pode ter sido causado, ainda, pelos baixos valores de condutividade elétrica, haja vista que o valor médio para esta variável foi de $0,483 \mathrm{dS} \mathrm{m}^{-1}$. Barbieri et al. (2010) evidenciam que soluções com condutividade elétrica em torno de $0,500 \mathrm{dS} \mathrm{m}^{-1}$ proporcionaram decréscimo de $52 \%$ na produção de alface, em relação a soluções com maior condutividade, sendo que estes autores verificaram o máximo desenvolvimento em soluções com valores entre 1,000 e $1,500 \mathrm{dS} \mathrm{m}^{-1}$.

\section{CONCLUSÕES}

Conclui-se que a proporção de peixes e vegetais utilizada neste trabalho foi insuficiente para atender a demanda nutricional das alfaces. As alfaces apresentaram desenvolvimento, entretanto, não correspondeu ao porte necessário para comercialização.

Houve um pequeno crescimento dos tambacus, o que foi diretamente influenciado por quedas de temperatura ocorridas e pelos níveis inadequados de amônia tóxica e nitrito encontrados no início do experimento. 
O sistema, de forma geral, não obteve resultados satisfatórios, de modo que as proporções utilizadas neste estudo não são indicadas para a produção de peixes e vegetais em aquaponia.

\section{AGRADECIMENTOS}

Ao Instituto Federal do Mato Grosso, pelo apoio ao desenvolvimento deste trabalho, e principalmente a sua Pró-Reitoria de Pesquisa e Inovação, pela concessão de auxílio financeiro. À FAPEMAT e ao CNPq, pela concessão de bolsas de iniciação científica aos discentes que participaram deste experimento. Aos estagiários do Laboratório de Piscicultura do IFMT Campus Cáceres.

\section{REFERÊNCIAS}

ADLER, P. R.; et al. Economic analysis of an aquaponic system for the integrated production of rainbow trout and plants. International Journal of Recirculating Aquaculture, v. 1, n. 1, p.15-34, 2000.

ALMEIDA, T. B. F.; et al. Avaliação nutricional de alface cultivada em soluções nutritivas suprimidas de macronutrientes. Revista Biotemas, v. 24, n. 2, p.27-36, jun. 2011.

ARAÚJO, A. F. Integração de plantas com espécies nativas de peixes em sistema de aquaponia. Dissertação (Mestrado em Aquicultura) - Centro de Ciências Agrárias, Universidade Federal de Santa Catarina, Florianópolis, 2015.

BARBIERI, E.; et al. Condutividade elétrica ideal para o cultivo hidropônico de alface em ambiente tropical. Horticultura Brasileira, v. 28, p.S303-S308, 2010.

BIALLI, A. P.; CRUZ, I. D. Aquaponia: Manual para produção em pequena escala. Disponível em: <http://docslide.com.br/documents/manual-de-aquaponia.html>. Acessado em: 18 jun. 2016.

BUSS, A. B.; et al. Desenvolvimento da aquaponia como alternativa de produção de alimentos saudáveis em perímetro urbano. In: Anais VI Seminário de Ensino, Pesquisa e Extensão - SENPEX, p. 1127-1132, 2015.

CARNEIRO, P. C.; et al. Produção integrada de peixes e vegetais em aquaponia. Aracaju: Embrapa Tabuleiros Costeiros, 2015.

CHOPIN, T.; SAWHNEY, M. Seaweeds and their mariculture In: STEELE, J. H.; TUREKIAN, K. K.; THROPE, S. A. Encyclopedia of ocean science. ed. 2, Oxford: Elsevier, 2009.

DIVER, S. Aquaponics - Integration of Hydroponics with Aquaculture. National Sustainable Agriculture Information Service, Washington, EUA, p.1-27, 2006. 
HUNDLEY, G. C. et al. Aproveitamento do efluente da produção de tilápia do Nilo para o crescimento de manjerona (Origanum majorana) e manjericão (Origanum basilicum) em sistemas de Aquaponia. Revista Brasileira de Agropecuária Sustentável, v.3, p.5155, 2013.

MACINTOSH, D.; PHILLIPS, M. Environmental issues in shrimp farming. In: SARAM, H.; SING, T. Proceedings of the 3th Global Conference on the Shrimp Industry, Hong Kong, INFOFISH, 1992, Kuala Lumper, Malaysia. v. 1, 1992.

MONTOYA, R. A. et al. Simulation of phosphorus dynamics in an intensive shrimp culture system: effects of feed formulation and feeding strategies. Ecological Modeling, v. 129, p.131-42, 2000.

MORO, G. V. et al. Monitoramento e manejo da qualidade da água em pisciculturas. In: Piscicultura de água doce: multiplicando conhecimentos. Brasília, DF: EMBRAPA, 2013, $440 \mathrm{p}$.

PHILLIPS, M. Marine overview. In: STEELE, J. H.; TUREKIAN, K.K.; THROPE, S.A. Encyclopedia of ocean science. ed. 2, Oxford: Elsevier, 2009.

QUILLÉRÉ, I. et al. An artificial productive ecosystem based on a fish/bacteria/plant association. 2. Performance. Agriculture, Ecosystems and Environment, v. 53, n. 1, p. 19-30, 1995.

RAKOCY, J. E.; HARGREAVES, J.A.; BAILEY, D.S. Effects of hydroponics vegetable production on water quality in a closed recirculating system. Journal World Aquaculture Society, v. 20, n. 3, p.64A, 1989.

RAKOCY, J. E.; et al. Aquaponic production of tilapia and basil: comparing a batch and staggered cropping system. Acta Horticulturae (ISHS), v. 648, n. 8, p.63-9, 2004.

SILVA, M. L. P.; et al. Caracterização de sintomas visuais de deficiências de macronutrientes em alface. Horticultura Brasileira, v. 29, n. 2, p.S3714-S3721, jul. 2011.

TISCHER, J. C.; SIQUEIRA NETO, M. Aquicultura em sistema fechado e controlado integração biodigestor/aquaponia - produção sustentável de peixes, hortaliças e bioenergia. Ensaios e Ciência: Ciências Biológicas, Agrárias e da Saúde. v. 16, n. 2, 2012.

TROELL, M. Integrated mariculture: its role in future aquaculture development. In: LOVATELLI, A.; et al. (eds). FAO/NACA Regional Workshop on the Future of Mariculture: a Regional Approach for Responsible Development in the Asia-Pacific Region. Guangzhou, China, 2006. FAO Fisheries Proceedings. N. 11. Rome, FAO. 2008. p.323-325, 2008. 